OPEN ACCESS

Edited by:

Raúl E. Russo,

Instituto de Investigaciones Biológicas Clemente Estable (IIBCE),

Uruguay

Reviewed by:

Flavio Zolessi,

University of the Republic, Uruguay Nicholas C. Spitzer, University of California, San Diego, United States

${ }^{*}$ Correspondence: Laura N. Borodinsky Inborodinsky@ucdavis.edu

Received: 02 October 2017 Accepted: 08 November 2017 Published: 23 November 2017

Citation: Borodinsky LN (2017) Xenopus laevis as a Model Organism for the Study of Spinal Cord Formation, Development, Function and Regeneration.

Front. Neural Circuits 11:90. doi: 10.3389/fncir.2017.00090

\section{Xenopus laevis as a Model Organism for the Study of Spinal Cord Formation, Development, Function and Regeneration}

\author{
Laura N. Borodinsky * \\ Department of Physiology \& Membrane Biology and Institute for Pediatric Regenerative Medicine, Shriners Hospital for \\ Children, University of California Davis School of Medicine, Sacramento, CA, United States
}

The spinal cord is the first central nervous system structure to develop during vertebrate embryogenesis, underscoring its importance to the organism. Because of its early formation, accessibility to the developing spinal cord in amniotes is challenging, often invasive and the experimental approaches amenable to model systems like mammals are limited. In contrast, amphibians, in general and the African-clawed frog Xenopus laevis, in particular, offer model systems in which the formation of the spinal cord, the differentiation of spinal neurons and glia and the establishment of spinal neuron and neuromuscular synapses can be easily investigated with minimal perturbations to the whole organism. The significant advances on gene editing and microscopy along with the recent completion of the Xenopus laevis genome sequencing have reinvigorated the use of this classic model species to elucidate the mechanisms of spinal cord formation, development, function and regeneration.

\footnotetext{
Keywords: neural tube defects, spinal cord injury, morphogenetic proteins, sensorimotor response, spinal neuron differentiation, axon guidance, calcium-dependent activity, neural plasticity
}

\section{INTRODUCTION}

The use of model organisms has been crucial to the progress toward understanding spinal cord function. The frog has been a pioneer animal model for the study of spinal cord formation, spinal cell specification and differentiation, spinal neuron axon guidance, neuromuscular junction formation and plasticity as well as spinal cord injury and regeneration.

Among amphibians, Xenopus laevis has been an advantageous frog species for the study of the spinal cord throughout development and in adulthood for several reasons. First, the Xenopus laevis egg is approximately $1-\mathrm{mm}$ diameter this means that is over 2300 times bigger than the mouse egg, the most popular vertebrate species. This allows for accessible manipulation of gene expression and genetic engineering by simple microinjection of constructs into the egg or fertilized embryo. Second, the eggshell is transparent, enabling the direct visualization of the first stages of spinal cord morphogenesis through non-invasive imaging approaches. Third, microinjections at individual blastomeres of the 2- to 32-cell stage embryos result in mosaic genetic manipulation, which can render internal control or tissue specificity for the targeted gene misexpression. Fourth, the development of Xenopus laevis spinal cord occurs much faster than for rodents and the developmental rate can be adjusted by growing animals at different temperatures. Fifth, the organization of the spinal cord is simpler than for higher vertebrates with overall fewer spinal cells, fewer types of spinal neurons and fewer 
connections between them. Nevertheless, the main kinds of spinal cord cells are represented, i.e., sensory neurons, interneurons, motor neurons and glial cells. Sixth, this species exhibits remarkable regenerative capacity during development, including the repair of the injured spinal cord, allowing for the identification of factors that enable successful spinal cord regeneration that might be missing in higher vertebrates. In spite of the unique characteristics of this species, many fundamental processes at the cellular and molecular level are highly conserved across vertebrates, making Xenopus laevis a valuable organism to study the mechanisms of human disease.

The features of Xenopus laevis mentioned above are few of the reasons why this species have become a successful model to study the first steps of neural induction and spinal cord morphogenesis, spinal neuron differentiation, synaptogenesis, including neuromuscular junction formation and maturation, as well as synaptic plasticity and regeneration after spinal cord injury. Here we compile both the pioneering and current studies that have made significant contributions at both establishing Xenopus laevis as a powerful model to study all aspects of spinal cord development and function and advancing the field of spinal cord research by uncovering the mechanisms underlying its development, plasticity and repair.

\section{FIRST STEP IN THE FORMATION OF THE SPINAL CORD: NEURAL INDUCTION IN Xenopus laevis}

Neural induction in vertebrates is the process by which a subset of ectodermal cells commits to the neural phenotype to originate the brain and spinal cord through interactions of the induced cells with neighboring cell layers (Spemann and Mangold, 1924). This event occurs very early in embryogenesis between fertilization and gastrulation, underscoring the importance of generating the neural tissue early on for the success of a viable organism. The first molecular signatures involved in this process were discovered through studies in Xenopus laevis. By assessing spatiotemporal expression of tissue-specific proteins, seminal studies showed that non-neural ectodermal cells express a set of proteins that are missing from neuroectodermal cells (Akers et al., 1986). Conversely, the expression of specific neural proteins like neural cell adhesion molecule (N-CAM), the homeobox transcription factor XiHbox8, are identified a couple of hours after Xenopus laevis gastrulation (Jacobson and Rutishauser, 1986; Sharpe et al., 1987), although the mRNA for N-CAM for instance is already detected during late gastrulation, after the mesoderm contacts the ectoderm (Kintner and Melton, 1987), suggesting that expression of neuralspecific proteins is a step that occurs after neural induction (Jacobson and Rutishauser, 1986). The identification of the inducing tissues resulted in a model that supports the interaction between the mesoderm and the dorsal ectoderm (Spemann, 1938; Smith and Slack, 1983; Sharpe et al., 1987). These interactions are organized by two centers identified in Xenopus laevis and called the Nieuwkoop center, located in dorsalvegetal cells, which expresses Nodal-related endomesodermal inducers and the blastula Chordin- and Noggin-expressing center located in dorsal animal cells that contains both prospective neuroectoderm and Spemann organizer precursor cells (Kuroda et al., 2004).

The factors secreted by inducing cells that drive the commitment to the neural phenotype include Noggin (Lamb et al., 1993), Chordin (Sasai et al., 1995), Follistatin (HemmatiBrivanlou et al., 1994), Xnr3 (Hansen et al., 1997), all inhibitors of the Bone Morphogenetic Protein (BMP) pathway and Fibroblast Growth Factor (FGF; Kengaku and Okamoto, 1993). The signaling elicited by these factors in the dorsal ectoderm involves translocation of Protein Kinase C to the membrane (Otte et al., 1988, 1991; Otte and Moon, 1992) and recruitment of signaling molecules like Smad10 (Lesueur and Graff, 1999; LeSueur et al., 2002) and the phosphorylation of Smad1 in the linker domain that inhibits its transcriptional activity and nuclear translocation, serving as an integration of several signaling pathways (Pera et al., 2003).

The two models that have emerged from these founding studies have supported a first model of ectodermal cells becoming neural by default, through inhibiting the BMP pathway; in the second model FGF instructs the dorsal ectodermal cells to become neural. More recently, the merging of these two models was proposed (Marchal et al., 2009). By antagonizing BMP signaling through the expression of a dominant negative (DN) cofactor of the BMP pathway, Xenopus epidermis was converted into neural tissue. However, this is prevented when FGF4 is knocked down; moreover, BMP signaling inhibition upregulates FGF4 expression. These findings led to the unified model for neural induction dependent on BMP inhibition that in turn activates FGF, which instructs expression of neural phenotype regulators (Marchal et al., 2009).

The factors that drive the neural phenotype downstream neural induction have also been identified by pioneering research in Xenopus laevis, and then findings extended to higher vertebrates. Prominent transcription factors are early downstream drivers of the neural commitment and include Zic3 (Nakata et al., 1997), SoxD (Mizuseki et al., 1998b), Zic-r1 and Sox2 (Mizuseki et al., 1998a), which then directly promote expression of proneural genes initiating neural and neuronal differentiation, or they work synergistically with other pathways to initiate expression of the neural phenotype (Mizuseki et al., 1998a).

More recent studies in this model system have revealed novel players in the process of neural induction and early neural specification. Norrin was identified as required for neuroectoderm specification by recruiting $\beta$-catenin and inhibiting $\mathrm{BMP} / \mathrm{TGF}-\beta$, thus coordinating these two major signaling pathways (Xu et al., 2012). Efforts have been made to identify the mechanisms responsible for global shifts in gene expression when ectodermal cells become restricted to the neural identity. A study in Xenopus laevis led to the discovery that the activity of histone methyltransferase is crucial for the upregulation in the expression of genes controlling neural induction, likely through the repression of the Oct4-related Xenopus gene Oct-25 (Nicetto et al., 2013). 


\section{SPINAL CORD FORMATION THROUGH THE LENS OF Xenopus laevis NEURULATION}

Once the neuroectoderm is induced the emerging neural plate, which appears as a dorsal thickening of the ectoderm, transits through dramatic morphogenic events to transform itself into the neural tube, the precursor of the spinal cord and the brain. Studies in Xenopus laevis have come once again to illuminate onto the cellular and molecular mechanisms that mediate neural tube formation. A combination of biochemical signals and mechanical forces orchestrate changes in cell shape, including apical constriction and cell elongation, necessary for the bending of the neural plate, the elevation of neural folds followed by the lateromedial migration and cell intercalation that leads to the mediolateral narrowing and anteroposterior elongation of the neural tissue, process known as convergent extension (for recent review see Sokol, 2016).

Apicobasal cell elongation accounts for thickening and narrowing of the neuroepithelium. In addition, mediolateral cell intercalation within each layer narrows the neural plate in the transverse axis while elongating it in the anteroposterior axis (Keller et al., 1992a,b,c). Neural plate shaping is closely followed by its bending. Initially, a furrow is formed in the notoplate as a result of the medial hinge point cell apical constriction. Then neural plate lateral edges rise forming incipient neural folds. Subsequent folding includes further neural fold elevation, convergence and rolling towards the midline. Continuing apicobasal elongation, cell apical constriction, crawling of lateral neural plate cells under the epidermis and continuing mediolateral intercalation are involved in this phase. During neural plate folding cell intercalation occurs at a higher rate compared to the shaping phase, accelerating convergent extension of the neuroepithelium (Jacobson et al., 1986). Subsequently, neural fold tips come into contact and fuse at the dorsal midline (Davidson and Keller, 1999). Finally, radial intercalation between the two cell layers forms a single-layered neural tube (Edlund et al., 2013).

As neurulation progresses different populations of cells in the neuroepithelium, it exhibit diverse types of cell behaviors (Wallingford, 2005). Apical constriction of superficial neural plate cells requires a precise spatiotemporal regulation of cytoskeletal and cell adhesion molecule dynamics. It was discovered in Xenopus that the actin binding protein Shroom is necessary for neural tube closure in amphibians and mammals by inducing apical constriction through enriching the apical neural plate surface with actin filaments and recruitment of the small GTPase Rap1 (Haigo et al., 2003). Neural plate cells exhibit $\mathrm{Ca}^{2+}$ dynamics (Wallingford et al., 2001) which elicit contraction events in these cells driven by transient contractile apical pools of actin (Christodoulou and Skourides, 2015).

Apical constriction also requires endocytosis at the apical neural plate cell membrane (Lee and Harland, 2010). A more recent study showed that through the activity of the Planar Cell Polarity pathway, Rab11-positive recycling endosomes localize to the medial apical cell junctions during neural tube formation; this polarization is necessary for neural plate folding (Ossipova et al., 2014). Moreover, a recently published study from our lab demonstrates that endocytosis of the adherens junction molecule C-cadherin is disrupted when folate receptor-1 is downregulated from the apical membranes of superficial neural plate cells, impairing neural plate cell apical constriction and neural tube formation (Balashova et al., 2017). The study provides a mechanism for folate action during neural tube formation that explains the vulnerability of this process to folate disturbances and the benefits of folate supplementation in the prevention of neural tube defects in humans (Blom et al., 2006). Our study, through the use of Xenopus laevis as a model system, uncovers specific functions of folate and its receptor beyond its role as a vitamin and enabler of DNA synthesis, since cell division is not necessary for neural tube formation in Xenopus (Harris and Hartenstein, 1991), in spite of the necessity of folate/folate receptor-1 for appropriate neural plate cell apical constriction and neural tube closure in this species (Balashova et al., 2017).

The process of convergent extension occurs through cell elongation and intercalation and is also dependent on $\mathrm{Ca}^{2+}$ dynamics (Wallingford et al., 2001). In addition, the non-canonical Wnt signaling pathway dependent on Disheveled is necessary for convergent extension (Wallingford and Harland, 2001). Other signaling pathway that has been identified as necessary in regulating microtubule dynamics for Xenopus neural fold elevation and cell intercalation is the Repulsive Guidance Molecule-Neogenin interaction (Kee et al., 2008). Microtubule polymerization is also the target of the $\mathrm{Zn}^{2+}$ transporter ZIP12 that when knocked down impairs Xenopus neural tube formation and neurite extension in developing spinal neurons (Chowanadisai et al., 2013; Figure 1).

\section{SPINAL NEURON DIFFERENTIATION AND SPINAL CORD MATURATION}

The development of spinal cord function relies on the assignment of specific identities to spinal neurons and glia followed by the establishment of synaptic connections. Our current understanding of the functional differentiation of spinal neurons has nourished from studies in Xenopus laevis. Pioneering studies by Spitzer and Baccaglini (1976) investigated the development of electrical excitability in developing spinal neurons both in vivo and in vitro. They found that shortly after neural tube closure $\mathrm{Ca}^{2+}$. dependent action potentials are elicited in immature sensory spinal neurons in vivo (Spitzer and Baccaglini, 1976). As maturation progresses, the action potential depends on both, $\mathrm{Na}^{+}$and $\mathrm{Ca}^{2+}$, and gradually, the $\mathrm{Na}^{+}$-driven component of the action potential becomes more predominant, until the $\mathrm{Ca}^{2+}$-dependent component disappears, after 3 days postfertilization (Spitzer and Baccaglini, 1976). The shift from the $\mathrm{Ca}^{2+}$-dependent to $\mathrm{Na}^{+}$-mediated action potential in developing spinal neurons depends on ion channel expression (O’Dowd, 1983; O’Dowd et al., 1988). 

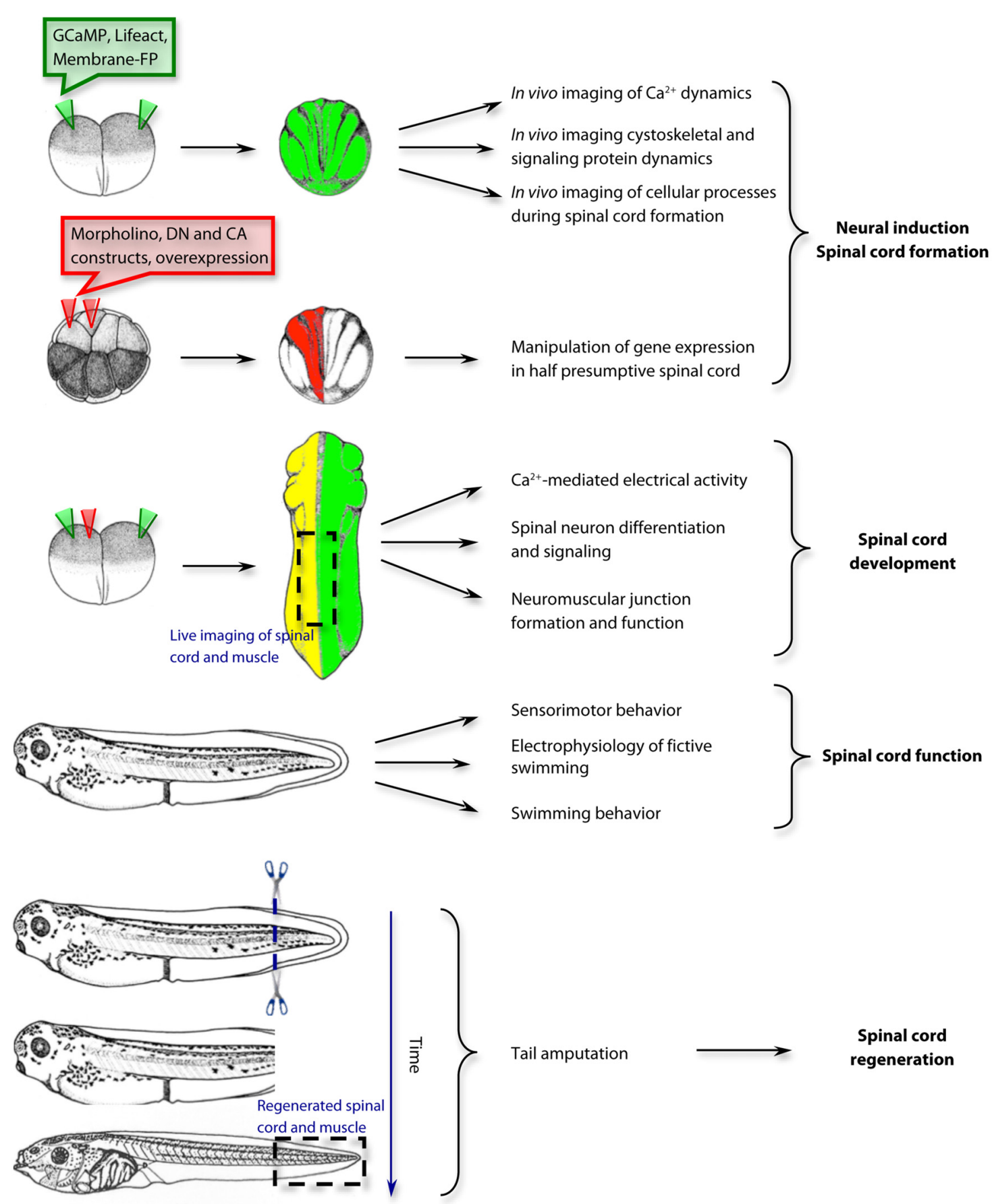

Tail amputation

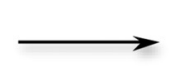

Spinal cord

regeneration

FIGURE 1 | Examples of approaches and applications for the study of spinal cord development, function and regeneration in Xenopus laevis. The use of Xenopus laevis as a model system spans from the first steps of neural induction and spinal cord formation to the mechanisms of spinal cord regeneration. GCaMP, genetically-encoded $\mathrm{Ca}^{2+}$ sensor; Lifeact, F-actin biosensor; Membrane-FP, Fluorescent protein tethered to the plasma membrane; DN, dominant negative; CA, constitutively active. Drawings of embryos and tadpoles were adapted from Xenbase.org and published previously by Nieuwkoop and Faber (1994); Copyright () 1994, Garland Publishing Inc.

In particular the upregulation of the delayed-rectifying $\mathrm{K}^{+}$current is crucial to the switch (Ribera and Spitzer, 1989; Burger and Ribera, 1996; Gurantz et al., 1996; Ribera, 1996).
The discovery of the $\mathrm{Ca}^{2+}$-dependent action potential in developing neurons opened up a prominent and influential research field focused on the role and the mechanisms of $\mathrm{Ca}^{2+}$-mediated electrical activity during nervous system 
development. In Xenopus laevis immature spinal neurons, the mechanisms underlying the spontaneous $\mathrm{Ca}^{2+}$ spikes involve the activation of T-type $\mathrm{Ca}^{2+}$ channels ( $\mathrm{Gu}$ and Spitzer, 1993) through a spontaneous initial depolarization which appear to be facilitated by neurotransmitter signaling (Root et al., 2008). This activity is important for the differentiation and maturation of spinal neurons (Gu and Spitzer, 1995). In particular, neurotransmitter phenotype specification is dependent on the level of $\mathrm{Ca}^{2+}$ spike activity, with higher frequencies driving the expression of inhibitory neurotransmitter phenotypes and lower frequencies driving expression of excitatory neurotransmitter phenotypes (Borodinsky et al., 2004; Marek et al., 2010). The changes in neurotransmitter phenotype are accompanied by changes in neurotransmitter receptor in target cells including the skeletal muscle in tadpole's neuromuscular junctions (Borodinsky and Spitzer, 2007; Figure 1).

We learned from studies on the patterning of ventral and dorsal spinal neuron identities in Xenopus laevis, the dependence of this process on the notochord; notochordless embryos exhibit fewer number of motor neurons and higher number of sensory neurons, and commissural interneuron axons cross the midline in a disorganized manner overall resulting in perturbed left-right alternation of the locomotive behavior (Clarke et al., 1991). Moreover, studies in our lab have demonstrated that the $\mathrm{Ca}^{2+}$-mediated electrical activity interacts with other essential developmental signaling pathways like Sonic hedgehog (Shh) and BMPs to orchestrate the differentiation of spinal neurons (Belgacem and Borodinsky, 2011, 2015; Swapna and Borodinsky, 2012; Borodinsky et al., 2015). Shh enhances activity of spinal neurons (Belgacem and Borodinsky, 2011) while BMP inhibits it (Swapna and Borodinsky, 2012). These studies identified novel non-canonical signaling pathways for morphogenetic protein action in the spinal cord. Furthermore, we discovered that $\mathrm{Ca}^{2+}$ spike activity is the mechanism by which Shh canonical signaling switches off during the early stages of spinal cord development (Belgacem and Borodinsky, 2015), phenomenon that is apparent in frogs and mice (Lee et al., 1997; Balaskas et al., 2012).

This model system has also been crucial in the identification of the mechanisms governing axon guidance of developing spinal neurons. Studies from the Poo laboratory first used Xenopus spinal neurons grown in culture to identify the signaling mechanisms underlying chemoattraction and repulsion of extending growth cones. They found that localized changes in levels of cyclic nucleotides transduce the signal of guidance cues like Netrin to change the direction of the growing axon (Lohof et al., 1992; Zheng et al., 1994; Ming et al., 1997, 1999, 2001; Song et al., 1997, 1998; Xiang et al., 2002). Further studies demonstrated that these mechanisms occur in vivo and the signaling is also dependent on localized $\mathrm{Ca}^{2+}$ dynamics in growth cones and filopodia (Gomez et al., 2001; Ming et al., 2001; Robles et al., 2003; Henley et al., 2004; Shim et al., 2005; Wang and Poo, 2005; Robles and Gomez, 2006).

In addition to the extension and direction of axon growth, Xenopus laevis spinal neurons have been used to determine the mechanisms underlying neuronal polarity through the establishement of dendrites vs. axons. Xenopus commissural spinal interneurons exposed to semaphorin $3 \mathrm{~A}$ revert the identity of axons to dendrites by activating $\mathrm{Ca}_{\mathrm{v}} 2.3$ channels through the cGMP-mediated activation of PKG (Nishiyama et al., 2011).

\section{ADVANCES IN THE UNDERSTANDING OF SPINAL CORD FUNCTION THROUGH RESEARCH IN XenopUS}

The spinal cord is in charge of sensorimotor functions in vertebrates. The elucidation of the mechanisms involved in the establishment of the sensorimotor function during development and the identification of the circuitry responsible for eliciting a specific sensorimotor response have been common foci of research. Хenopus offers an excellent system to study these aspects of spinal cord development and function. In particular, two important fronts of research have benefited greatly from the studies done in Xenopus; one is the research on the mechanisms of neuromuscular junction plasticity during development, and the other is the identification of the circuitries in the spinal cord that elicit the simple sensorimotor reflexes and the more complex locomotor behaviors (Figure 1).

Taking advantage of the ease of in vivo time-lapse imaging in developing tadpoles, the Cline lab fluorescently labeled spinal motor neuron axons and nicotinic receptor clusters in muscle cells through electroporation, and demonstrated that axon branches and synaptogenesis are concurrent and dynamic (Javaherian and Cline, 2005). They further identified the Candidate Plasticity Gene 15 as necessary for axon arborization and promotion of synaptogenesis at the neuromuscular junction (Javaherian and Cline, 2005). The rules of pre and postsynaptic interactions that govern plasticity events such as synaptic depression and potentiation were first tested in Xenopus laevis neuron-muscle connections, a simple prototype of developing vertebrate neuromuscular junction. A transient increase in intracellular $\mathrm{Ca}^{2+}$ concentration in the connected muscle cell triggers a decrease in neurotransmitter release from the presynaptic motor neuron. This depression is persistent and dependent on the connection with the affected muscle cell and not on a secreted extracellular factor (Cash et al., 1996). In contrast, a burst of action potentials in the presynaptic motor neuron leads to a sustained potentiation of synaptic activity of the neuromuscular junction due to increase in probability of neurotransmitter release (Wan and Poo, 1999). Neurotrophins were identified in Xenopus neuromuscular junction studies as effective mediators of synaptic potentiation. In particular BrainDerived Neurotrophic Factor (BDNF) was found to potentiate synaptic efficacy, through cAMP signaling (Boulanger and Poo, 1999a), when paired with a presynaptic depolarization of the motor neuron within a specific timing (Boulanger and Poo, 1999b). A more recent study has further the understanding of BDNF action on activity-dependent neuromuscular junction remodeling by demonstrating that stimulating motor neurons induces the maturation of BDNF in the presynapse. While immature BDNF promotes retraction of the less active synaptic terminal, mature BDNF leads to stabilization of the active terminal (Je et al., 2012). 
With regard to the understanding of the circuitry underlying locomotor behavior in vertebrates, seminal work from Roberts et al. (1981) took advantage of the simplicity of the neuroanatomy and behavior of swimming larvae to answer fundamental questions on the connectivity and organization of the underlying neuronal networks. They discovered that the rhythmicity of the swimming behavior resides in the spinal cord and is inherent to each side of the cord (Roberts et al., 1981). They also found that the commissural inhibitory spinal interneurons are necessary for the strict alternation between left and right motor neuron activity (Roberts et al., 1981). Other studies have been equally insightful at revealing the circuitry underlying the sensorimotor response upon touch and the mechanisms responsible for the relationship between the locomotor central pattern generator and motor neuron activity (Sillar and Roberts, 1988; Li et al., 2003; Buhl et al., 2015).

The neurophysiological substrate for the acquisition of progressive refinement in the locomotor system has been investigated by Sillar and Roberts (1988). They found that changes in motor neuron firing properties and patterns of innervation of the axial musculature in Xenopus laevis larvae change during the first day after hatching so that different pools of motor neurons progressively innervate a more restricted region of muscle fibers (Zhang et al., 2011). The motor neuron firing probability transitions from a single action potential per swim cycle right after hatching to different firing probabilities 1 day after hatching, when diverse types of swimming behavior are elicited (Zhang et al., 2011).

\section{SPINAL CORD REGENERATION}

All the aspects of spinal cord development and function discussed above highlight the usefulness of Xenopus as a model system because the processes occurring in the frog are conserved across vertebrates including mammals, with the advantage of being a simpler system, more amenable to in vivo and in vitro approaches, live-imaging and physiology studies. Thus, this model system enables the identification of the molecular and cellular mechanisms underlying the conserved and fundamental processes. Other features of Xenopus make this animal model unique among other systems. This uniqueness can also be advantageous; for instance, from investigating the mechanisms that make this system different than other vertebrates we can better understand the potential limitations that other species including humans face. Before metamorphosis, the regenerative capacity of frogs, and Xenopus in particular, is remarkable. Even the adult frog is able to regenerate certain axons like the optic nerve but not the spinal axons, due to some non-permissive factors generated by the spinal cord oligodendrocytes and myelin (Lang et al., 1995). Outstandingly, when the tadpole's tail is amputated, all the tissues including skin, notochord, muscle and spinal cord regenerate (Figure 1). Every tissue regenerates from a dedicated pool of stem cells that are activated upon amputation (Gargioli and Slack, 2004). Interestingly, the Xenopus tadpole tail exhibits this regenerative capacity throughout development with the exception of a so-called refractory period when the tail heals without regeneration. This further uniqueness enables the study within the same model system of the factors that are permissive of the regenerative process. The Slack laboratory took advantage of this aspect of Xenopus laevis and discovered that BMP and Notch signaling (downstream of BMP) are necessary for tail regeneration and sufficient for overriding the refractory period (Beck et al., 2003). BMP signaling appears to be required for appropriate neural cell proliferation to replenish the spinal cord (Beck et al., 2006). It has also been shown that a restricted rate of apoptosis is required during the first $24 \mathrm{~h}$ post injury for successful regeneration during the permissive stages and that a more extensive apoptosis may interfere with appropriate regeneration during the refractory stages (Tseng et al., 2007). The extent of apoptosis appears to be controlled by the activity of the V-ATPase $\mathrm{H}^{+}$pump that is upregulated in the regenerating tissue and repolarizes the membrane potential of regenerating cells after an initial depolarization is triggered by the injury (Adams et al., 2007). In agreement with these studies we found that cells from the regenerating tail exhibit spontaneous $\mathrm{Ca}^{2+}$ transients during the first $24 \mathrm{~h}$ post amputation. Suppressing this activity impairs tail regeneration, apparently by impairing activation of stem cells for replenishing the spinal cord and muscle ( $\mathrm{Tu}$ and Borodinsky, 2014). In recent studies gene expression profiles during tail regeneration were collected from Xenopus laevis (Lee-Liu et al., 2014) and tropicalis (Love et al., 2011) amputated tadpoles at different periods post injury and in regenerative and non-regenerative stages. From these excellent resources, insightful studies have emerged demonstrating that injury increases production of reactive oxygen species that are upstream $W n t / \beta$-catenin and the upregulation of FGF20 expression, which contribute to the signaling mechanisms necessary for tail regeneration (Love et al., 2013).

\section{CONCLUDING REMARKS}

Xenopus is a classic model for embryology and physiology research and has been perfectly suited for studies on the formation, development, maturation and repair of the spinal cord. The recent completion of the sequencing of the Xenopus laevis genome (Session et al., 2016), and Xenopus tropicalis genome since 2010 (Hellsten et al., 2010), allows for the use of both in genetic studies; along with the remarkable advances in systems biology, including genomics, metabolomics and proteomics, the opportunities for discovery that this model system offers are reinvigorated (LombardBanek et al., 2017; Tandon et al., 2017). Additionally the accessibility of novel approaches for gene editing like TALENs (transcription activator-like effector nucleases) and CRISPR-Cas (clustered regularly interspaced short palindromic repeatsCRISPR associated nucleases) expand the use of Xenopus as a genetically tractable model for loss and gain of function studies (Tandon et al., 2017). Salient questions remain in every aspect of spinal cord research that was covered in this review and other aspects that were not included. The signaling mechanisms affecting the formation of the spinal 
cord and responsible for birth defects like spina bifida demand further investigation (Wallingford et al., 2013). The deeper understanding of the mechanisms governing the switch from neural stem cell to neuron is important for both the prevention of spinal cord malformations during development and the promotion of the recovery and regeneration in patients with spinal cord injury. Finally, studies on the assembly and plasticity of circuitry underlying spinal cord function can benefit from the advances in microscopy and optogenetics to dissect out the precise interactions among different types of neurons. The prediction is that Xenopus will continue to offer an advantageous platform for hypothesis-driven research that will contribute to the understanding of spinal cord development, function and disease.

\section{REFERENCES}

Adams, D. S., Masi, A., and Levin, M. (2007). $\mathrm{H}^{+}$pump-dependent changes in membrane voltage are an early mechanism necessary and sufficient to induce Xenopus tail regeneration. Development 134, 1323-1335. doi: 10.1242/dev. 02812

Akers, R. M., Phillips, C. R., and Wessells, N. K. (1986). Expression of an epidermal antigen used to study tissue induction in the early Xenopus laevis embryo. Science 231, 613-616. doi: 10.1126/science.3945801

Balashova, O. A., Visina, O., and Borodinsky, L. N. (2017). Folate receptor 1 is necessary for neural plate cell apical constriction during Xenopus neural tube formation. Development 144, 1518-1530. doi: 10.1242/dev.137315

Balaskas, N., Ribeiro, A., Panovska, J., Dessaud, E., Sasai, N., Page, K. M., et al. (2012). Gene regulatory logic for reading the Sonic Hedgehog signaling gradient in the vertebrate neural tube. Cell 148, 273-284. doi: 10.1016/j.cell. 2011.10.047

Beck, C. W., Christen, B., Barker, D., and Slack, J. M. (2006). Temporal requirement for bone morphogenetic proteins in regeneration of the tail and limb of Xenopus tadpoles. Mech. Dev. 123, 674-688. doi: 10.1016/j.mod.2006. 07.001

Beck, C. W., Christen, B., and Slack, J. M. (2003). Molecular pathways needed for regeneration of spinal cord and muscle in a vertebrate. Dev. Cell 5, 429-439. doi: 10.1016/s1534-5807(03)00233-8

Belgacem, Y. H., and Borodinsky, L. N. (2011). Sonic hedgehog signaling is decoded by calcium spike activity in the developing spinal cord. Proc. Natl. Acad. Sci. U S A 108, 4482-4487. doi: 10.1073/pnas.1018217108

Belgacem, Y. H., and Borodinsky, L. N. (2015). Inversion of Sonic hedgehog action on its canonical pathway by electrical activity. Proc. Natl. Acad. Sci. U S A 112, 4140-4145. doi: 10.1073/pnas.1419690112

Blom, H. J., Shaw, G. M., den Heijer, M., and Finnell, R. H. (2006). Neural tube defects and folate: case far from closed. Nat. Rev. Neurosci. 7, 724-731. doi: 10.1038/nrn1986

Borodinsky, L. N., Belgacem, Y. H., Swapna, I., Visina, O., Balashova, O. A., Sequerra, E. B., et al. (2015). Spatiotemporal integration of developmental cues in neural development. Dev. Neurobiol. 75, 349-359. doi: 10.1002/dneu. 22254

Borodinsky, L. N., Root, C. M., Cronin, J. A., Sann, S. B., Gu, X., and Spitzer, N. C. (2004). Activity-dependent homeostatic specification of transmitter expression in embryonic neurons. Nature 429, 523-530. doi: 10.1038/nature02518

Borodinsky, L. N., and Spitzer, N. C. (2007). Activity-dependent neurotransmitterreceptor matching at the neuromuscular junction. Proc. Natl. Acad. Sci. US A 104, 335-340. doi: 10.1073/pnas.0607450104

Boulanger, L., and Poo, M. M. (1999a). Gating of BDNF-induced synaptic potentiation by cAMP. Science 284, 1982-1984. doi: 10.1126/science.284.54 22.1982

Boulanger, L., and Poo, M. M. (1999b). Presynaptic depolarization facilitates neurotrophin-induced synaptic potentiation. Nat. Neurosci. 2, 346-351. doi: $10.1038 / 7258$

\section{AUTHOR CONTRIBUTIONS}

LNB wrote the manuscript.

\section{FUNDING}

The work in the lab has been supported by the Basil O'Connor Starter Scholar Research Award Grant 5-FY09-131 from the March of Dimes Foundation, Esther A. and Joseph Klingenstein Fund, Klingenstein Foundation Award in Neuroscience, National Science Foundation (NSF) 1120796, NIH-National Institute of Neurological Disorders and Stroke (NINDS) R01NS073055 and Shriners Hospital for Children 86500-NCA, 85220-NCA and 85300-NCA grants to LNB.

Buhl, E., Soffe, S. R., and Roberts, A. (2015). Sensory initiation of a co-ordinated motor response: synaptic excitation underlying simple decision-making. J. Physiol. 593, 4423-4437. doi: 10.1113/JP270792

Burger, C., and Ribera, A. B. (1996). Xenopus spinal neurons express Kv2 potassium channel transcripts during embryonic development. J. Neurosci. 16, 1412-1421.

Cash, S., Zucker, R. S., and Poo, M. M. (1996). Spread of synaptic depression mediated by presynaptic cytoplasmic signaling. Science 272, 998-1001. doi: $10.1126 /$ science.272.5264.998

Chowanadisai, W., Graham, D. M., Keen, C. L., Rucker, R. B., and Messerli, M. A. (2013). Neurulation and neurite extension require the zinc transporter ZIP12 (slc39a12). Proc. Natl. Acad. Sci. U S A 110, 9903-9908. doi: 10.1073/pnas. 1222142110

Christodoulou, N., and Skourides, P. A. (2015). Cell-Autonomous $\mathrm{Ca}^{2+}$ Flashes elicit pulsed contractions of an apical actin network to drive apical constriction during neural tube closure. Cell Rep. 13, 2189-2202. doi: 10.1016/j.celrep.2015. 11.017

Clarke, J. D., Holder, N., Soffe, S. R., and Storm-Mathisen, J. (1991). Neuroanatomical and functional analysis of neural tube formation in notochordless Xenopus embryos; laterality of the ventral spinal cord is lost. Development 112, 499-516.

Davidson, L. A., and Keller, R. E. (1999). Neural tube closure in Xenopus laevis involves medial migration, directed protrusive activity, cell intercalation and convergent extension. Development 126, 4547-4556.

Edlund, A. F., Davidson, L. A., and Keller, R. E. (2013). Cell segregation, mixing, and tissue pattern in the spinal cord of the Xenopus laevis neurula. Dev. Dyn. 242, 1134-1146. doi: 10.1002/dvdy.24004

Gargioli, C., and Slack, J. M. (2004). Cell lineage tracing during Xenopus tail regeneration. Development 131, 2669-2679. doi: 10.1242/dev. 01155

Gomez, T. M., Robles, E., Poo, M., and Spitzer, N. C. (2001). Filopodial calcium transients promote substrate-dependent growth cone turning. Science 291, 1983-1987. doi: 10.1126/science. 1056490

$\mathrm{Gu}$, X., and Spitzer, N. C. (1993). Low-threshold $\mathrm{Ca}^{2+}$ current and its role in spontaneous elevations of intracellular $\mathrm{Ca}^{2+}$ in developing Xenopus neurons. J. Neurosci. 13, 4936-4948.

$\mathrm{Gu}$, X., and Spitzer, N. C. (1995). Distinct aspects of neuronal differentiation encoded by frequency of spontaneous $\mathrm{Ca}^{2+}$ transients. Nature $375,784-787$. doi: $10.1038 / 375784 \mathrm{a} 0$

Gurantz, D., Ribera, A. B., and Spitzer, N. C. (1996). Temporal regulation of Shaker- and Shab-like potassium channel gene expression in single embryonic spinal neurons during $\mathrm{K}^{+}$current development. J. Neurosci. 16, 3287-3295.

Haigo, S. L., Hildebrand, J. D., Harland, R. M., and Wallingford, J. B. (2003). Shroom induces apical constriction and is required for hingepoint formation during neural tube closure. Curr. Biol. 13, 2125-2137. doi: 10.1016/s09609822(03)00910-2 
Hansen, C. S., Marion, C. D., Steele, K., George, S., and Smith, W. C. (1997). Direct neural induction and selective inhibition of mesoderm and epidermis inducers by Xnr3. Development 124, 483-492.

Harris, W. A., and Hartenstein, V. (1991). Neuronal determination without cell division in Xenopus embryos. Neuron 6, 499-515. doi: 10.1016/08966273(91)90053-3

Hellsten, U., Harland, R. M., Gilchrist, M. J., Hendrix, D., Jurka, J., Kapitonov, V., et al. (2010). The genome of the Western clawed frog Xenopus tropicalis. Science 328, 633-636. doi: 10.1126/science.1183670

Hemmati-Brivanlou, A., Kelly, O. G., and Melton, D. A. (1994). Follistatin, an antagonist of activin, is expressed in the Spemann organizer and displays direct neuralizing activity. Cell 77, 283-295. doi: 10.1016/0092-8674(94)90320-4

Henley, J. R., Huang, K. H., Wang, D., and Poo, M. M. (2004). Calcium mediates bidirectional growth cone turning induced by myelin-associated glycoprotein. Neuron 44, 909-916. doi: 10.1016/j.neuron.2004.11.030

Jacobson, A. G., Oster, G. F., Odell, G. M., and Cheng, L. Y. (1986). Neurulation and the cortical tractor model for epithelial folding. J. Embryol. Exp. Morphol. 96, 19-49.

Jacobson, M., and Rutishauser, U. (1986). Induction of neural cell adhesion molecule (NCAM) in Xenopus embryos. Dev. Biol. 116, 524-531. doi: 10.1016/0012-1606(86)90153-3

Javaherian, A., and Cline, H. T. (2005). Coordinated motor neuron axon growth and neuromuscular synaptogenesis are promoted by CPG15 in vivo. Neuron 45 , 505-512. doi: 10.1016/j.neuron.2004.12.051

Je, H. S., Yang, F., Ji, Y., Nagappan, G., Hempstead, B. L., and Lu, B. (2012). Role of pro-brain-derived neurotrophic factor (proBDNF) to mature BDNF conversion in activity-dependent competition at developing neuromuscular synapses. Proc. Natl. Acad. Sci. U S A 109, 15924-15929. doi: 10.1073/pnas. 1207767109

Kee, N., Wilson, N., De Vries, M., Bradford, D., Key, B., and Cooper, H. M. (2008). Neogenin and RGMa control neural tube closure and neuroepithelial morphology by regulating cell polarity. J. Neurosci. 28, 12643-12653. doi: 10.1523/JNEUROSCI.4265-08.2008

Keller, R., Shih, J., and Domingo, C. (1992a). The patterning and functioning of protrusive activity during convergence and extension of the Xenopus organiser. Dev. 116, 81-91.

Keller, R., Shih, J., and Sater, A. (1992b). The cellular basis of the convergence and extension of the Xenopus neural plate. Dev. Dyn. 193, 199-217. doi: 10.1002/aja. 1001930302

Keller, R., Shih, J., Sater, A. K., and Moreno, C. (1992c). Planar induction of convergence and extension of the neural plate by the organizer of Xenopus. Dev. Dyn. 193, 218-234. doi: 10.1002/aja.1001930303

Kengaku, M., and Okamoto, H. (1993). Basic fibroblast growth factor induces differentiation of neural tube and neural crest lineages of cultured ectoderm cells from Xenopus gastrula. Development 119, 1067-1078.

Kintner, C. R., and Melton, D. A. (1987). Expression of Xenopus N-CAM RNA in ectoderm is an early response to neural induction. Development 99, 311-325.

Kuroda, H., Wessely, O., and De Robertis, E. M. (2004). Neural induction in Xenopus: requirement for ectodermal and endomesodermal signals via Chordin, Noggin, $\beta$-Catenin, and Cerberus. PLoS Biol. 2:E92. doi: 10.1371/journal.pbio.0020092

Lamb, T. M., Knecht, A. K., Smith, W. C., Stachel, S. E., Economides, A. N., Stahl, N., et al. (1993). Neural induction by the secreted polypeptide noggin. Science 262, 713-718. doi: 10.1126/science.8235591

Lang, D. M., Rubin, B. P., Schwab, M. E., and Stuermer, C. A. (1995). CNS myelin and oligodendrocytes of the Xenopus spinal cord-but not optic nerve-are nonpermissive for axon growth. J. Neurosci. 15, 99-109.

Lee, J. Y., and Harland, R. M. (2010). Endocytosis is required for efficient apical constriction during Xenopus gastrulation. Curr. Biol. 20, 253-258. doi: 10.1016/j.cub.2009.12.021

Lee-Liu, D., Moreno, M., Almonacid, L. I., Tapia, V. S., Muüoz, R., von Marées, J., et al. (2014). Genome-wide expression profile of the response to spinal cord injury in Xenopus laevis reveals extensive differences between regenerative and non-regenerative stages. Neural Dev. 9:12. doi: 10.1186/1749 $-8104-9-12$

Lee, J., Platt, K. A., Censullo, P., and Ruiz I Altaba, A. (1997). Gli1 is a target of Sonic hedgehog that induces ventral neural tube development. Development $124,2537-2552$.
Lesueur, J. A., and Graff, J. M. (1999). Spemann organizer activity of Smad10. Development 126, 137-146.

LeSueur, J. A., Fortuno, E. S. III, McKay, R. M., and Graff, J. M. (2002). Smad10 is required for formation of the frog nervous system. Dev. Cell 2, 771-783. doi: 10.1016/s1534-5807(02)00172-7

Li, W. C., Soffe, S. R., and Roberts, A. (2003). The spinal interneurons and properties of glutamatergic synapses in a primitive vertebrate cutaneous flexion reflex. J. Neurosci. 23, 9068-9077.

Lohof, A. M., Quillan, M., Dan, Y., and Poo, M. M. (1992). Asymmetric modulation of cytosolic cAMP activity induces growth cone turning. J. Neurosci. 12, 1253-1261.

Lombard-Banek, C., Portero, E. P., Onjiko, R. M., and Nemes, P. (2017). Newgeneration mass spectrometry expands the toolbox of cell and developmental biology. Genesis 55:e23012. doi: 10.1002/dvg.23012

Love, N. R., Chen, Y., Bonev, B., Gilchrist, M. J., Fairclough, L., Lea, R., et al. (2011). Genome-wide analysis of gene expression during Xenopus tropicalis tadpole tail regeneration. BMC Dev. Biol. 11:70. doi: 10.1186/1471-213x-11-70

Love, N. R., Chen, Y., Ishibashi, S., Kritsiligkou, P., Lea, R., Koh, Y., et al. (2013). Amputation-induced reactive oxygen species are required for successful Xenopus tadpole tail regeneration. Nat. Cell Biol. 15, 222-228. doi: $10.1038 /$ ncb2659

Marchal, L., Luxardi, G., Thomé, V., and Kodjabachian, L. (2009). BMP inhibition initiates neural induction via FGF signaling and Zic genes. Proc. Natl. Acad. Sci. U S A 106, 17437-17442. doi: 10.1073/pnas.0906352106

Marek, K. W., Kurtz, L. M., and Spitzer, N. C. (2010). cJun integrates calcium activity and tlx 3 expression to regulate neurotransmitter specification. Nat. Neurosci. 13, 944-950. doi: 10.1038/nn.2582

Ming, G., Henley, J., Tessier-Lavigne, M., Song, H., and Poo, M. (2001). Electrical activity modulates growth cone guidance by diffusible factors. Neuron 29, 441-452. doi: 10.1016/s0896-6273(01)00217-3

Ming, G. L., Song, H. J., Berninger, B., Holt, C. E., Tessier-Lavigne, M., and Poo, M. M. (1997). cAMP-dependent growth cone guidance by netrin-1. Neuron 19, 1225-1235. doi: 10.1016/s0896-6273(00)80414-6

Ming, G., Song, H., Berninger, B., Inagaki, N., Tessier-Lavigne, M., and Poo, M. (1999). Phospholipase C- $\gamma$ and phosphoinositide 3-kinase mediate cytoplasmic signaling in nerve growth cone guidance. Neuron 23, 139-148. doi: 10.1016/s0896-6273(00)80760-6

Mizuseki, K., Kishi, M., Matsui, M., Nakanishi, S., and Sasai, Y. (1998a). Xenopus Zic-related-1 and Sox-2, two factors induced by chordin, have distinct activities in the initiation of neural induction. Development 125, 579-587.

Mizuseki, K., Kishi, M., Shiota, K., Nakanishi, S., and Sasai, Y. (1998b). SoxD: an essential mediator of induction of anterior neural tissues in Xenopus embryos. Neuron 21, 77-85. doi: 10.1016/S0896-6273(00)80516-4

Nakata, K., Nagai, T., Aruga, J., and Mikoshiba, K. (1997). Xenopus Zic3, a primary regulator both in neural and neural crest development. Proc. Natl. Acad. Sci. US A 94, 11980-11985. doi: 10.1073/pnas.94.22.11980

Nicetto, D., Hahn, M., Jung, J., Schneider, T. D., Straub, T., David, R., et al. (2013). Suv4-20h histone methyltransferases promote neuroectodermal differentiation by silencing the pluripotency-associated Oct-25 gene. PLoS Genet. 9:e1003188. doi: 10.1371/journal.pgen.1003188

Nieuwkoop, P. D., and Faber, J. (Eds). (1994). Normal Table of Xenopus laevis (Daudin): A Systematical and Chronological Survey of the Development from the Fertilized Egg Till the End of Metamorphosis. New York, NY: Garland Publishing Inc.

Nishiyama, M., Togashi, K., von Schimmelmann, M. J., Lim, C. S., Maeda, S., Yamashita, N., et al. (2011). Semaphorin 3A induces Cav2.3 channeldependent conversion of axons to dendrites. Nat. Cell Biol. 13, 676-685. doi: $10.1038 /$ ncb2255

O'Dowd, D. K. (1983). RNA synthesis dependence of action potential development in spinal cord neurones. Nature 303, 619-621. doi: 10.1038/303 $619 \mathrm{a} 0$

O’Dowd, D. K., Ribera, A. B., and Spitzer, N. C. (1988). Development of voltagedependent calcium, sodium and potassium currents in Xenopus spinal neurons. J. Neurosci. 8, 792-805.

Ossipova, O., Kim, K., Lake, B. B., Itoh, K., Ioannou, A., and Sokol, S. Y. (2014). Role of Rab11 in planar cell polarity and apical constriction during vertebrate neural tube closure. Nat. Commun. 5:3734. doi: 10.1038/ncomm s4734 
Otte, A. P., Koster, C. H., Snoek, G. T., and Durston, A. J. (1988). Protein kinase C mediates neural induction in Xenopus laevis. Nature 334, 618-620. doi: $10.1038 / 334618 \mathrm{a} 0$

Otte, A. P., Kramer, I. M., and Durston, A. J. (1991). Protein kinase C and regulation of the local competence of Xenopus ectoderm. Science 251, 570-573. doi: 10.1126/science.1990433

Otte, A. P., and Moon, R. T. (1992). Protein kinase C isozymes have distinct roles in neural induction and competence in Xenopus. Cell 68, 1021-1029. doi: 10.1016/0092-8674(92)90074-m

Pera, E. M., Ikeda, A., Eivers, E., and De Robertis, E. M. (2003). Integration of IGF, FGF, and anti-BMP signals via Smadl phosphorylation in neural induction. Genes Dev. 17, 3023-3028. doi: 10.1101/gad.1153603

Ribera, A. B. (1996). Homogeneous development of electrical excitability via heterogeneous ion channel expression. J. Neurosci. 16, 1123-1130.

Ribera, A. B., and Spitzer, N. C. (1989). A critical period of transcription required for differentiation of the action potential of spinal neurons. Neuron 2, 1055-1062. doi: 10.1016/0896-6273(89)90229-8

Roberts, A., Kahn, J. A., Soffe, S. R., and Clarke, J. D. (1981). Neural control of swimming in a vertebrate. Science 213, 1032-1034. doi: 10.1126/science. 7196599

Robles, E., and Gomez, T. M. (2006). Focal adhesion kinase signaling at sites of integrin-mediated adhesion controls axon pathfinding. Nat. Neurosci. 9, 1274-1283. doi: $10.1038 / \mathrm{nn} 1762$

Robles, E., Huttenlocher, A., and Gomez, T. M. (2003). Filopodial calcium transients regulate growth cone motility and guidance through local activation of calpain. Neuron 38, 597-609. doi: 10.1016/s0896-6273(03)00260-5

Root, C. M., Velázquez-Ulloa, N. A., Monsalve, G. C., Minakova, E., and Spitzer, N. C. (2008). Embryonically expressed GABA and glutamate drive electrical activity regulating neurotransmitter specification. J. Neurosci. 28, 4777-4784. doi: 10.1523/JNEUROSCI.4873-07.2008

Sasai, Y., Lu, B., Steinbeisser, H., and De Robertis, E. M. (1995). Regulation of neural induction by the Chd and Bmp-4 antagonistic patterning signals in Xenopus. Nature 376, 333-336. doi: 10.1038/376333a0

Session, A. M., Uno, Y., Kwon, T., Chapman, J. A., Toyoda, A., Takahashi, S., et al. (2016). Genome evolution in the allotetraploid frog Xenopus laevis. Nature 538, 336-343. doi: 10.1038/nature19840

Sharpe, C. R., Fritz, A., De Robertis, E. M., and Gurdon, J. B. (1987). A homeoboxcontaining marker of posterior neural differentiation shows the importance of predetermination in neural induction. Cell 50, 749-758. doi: 10.1016/00928674(87)90333-3

Shim, S., Goh, E. L., Ge, S., Sailor, K., Yuan, J. P., Roderick, H. L., et al. (2005). XTRPC1-dependent chemotropic guidance of neuronal growth cones. Nat. Neurosci. 8, 730-735. doi: 10.1038/nn1459

Sillar, K. T., and Roberts, A. (1988). A neuronal mechanism for sensory gating during locomotion in a vertebrate. Nature 331, 262-265. doi: 10.1038/33 $1262 \mathrm{a} 0$

Smith, J. C., and Slack, J. M. (1983). Dorsalization and neural induction: properties of the organizer in Xenopus laevis. J. Embryol. Exp. Morphol. 78, 299-317.

Sokol, S. Y. (2016). Mechanotransduction during vertebrate neurulation. Curr. Top. Dev. Biol. 117, 359-376. doi: 10.1016/bs.ctdb.2015.11.036

Song, H., Ming, G., He, Z., Lehmann, M., McKerracher, L., Tessier-Lavigne, M., et al. (1998). Conversion of neuronal growth cone responses from repulsion to attraction by cyclic nucleotides. Science 281, 1515-1518. doi: 10.1126/science. 281.5382.1515

Song, H. J., Ming, G. L., and Poo, M. M. (1997). cAMP-induced switching in turning direction of nerve growth cones. Nature 388, 275-279. doi: $10.1038 / 40864$

Spemann, H. (1938). Embryonic Development and Induction. New Haven, CT: Yale University Press; H. Milford, Oxford University Press.
Spemann, H., and Mangold, H. (1924). über induktion von embryonalanlagen durch implantation artfremder organisatoren. Arch. Mikrosk. Anat. Entwickl. 100, 599-638. doi: 10.1007/BF02108133

Spitzer, N. C., and Baccaglini, P. I. (1976). Development of the action potential in embryo amphibian neurons in vivo. Brain Res. 107, 610-616. doi: 10.1016/0006-8993(76)90148-7

Swapna, I., and Borodinsky, L. N. (2012). Interplay between electrical activity and bone morphogenetic protein signaling regulates spinal neuron differentiation. Proc. Natl. Acad. Sci. U S A 109, 16336-16341. doi: 10.1073/pnas.1202818109

Tandon, P., Conlon, F., Furlow, J. D., and Horb, M. E. (2017). Expanding the genetic toolkit in Xenopus: approaches and opportunities for human disease modeling. Dev. Biol. 426, 325-335. doi: 10.1016/j.ydbio.2016.04.009

Tseng, A.-S., Adams, D. S., Qiu, D., Koustubhan, P., and Levin, M. (2007). Apoptosis is required during early stages of tail regeneration in Xenopus laevis. Dev. Biol. 301, 62-69. doi: 10.1016/j.ydbio.2006.10.048

Tu, M. K., and Borodinsky, L. N. (2014). Spontaneous calcium transients manifest in the regenerating muscle and are necessary for skeletal muscle replenishment. Cell Calcium 56, 34-41. doi: 10.1016/j.ceca.2014.04.004

Wallingford, J. B. (2005). Neural tube closure and neural tube defects: studies in animal models reveal known knowns and known unknowns. Am. J. Med. Genet. C Semin. Med. Genet. 135C, 59-68. doi: 10.1002/ajmg.c.30054

Wallingford, J. B., Ewald, A. J., Harland, R. M., and Fraser, S. E. (2001). Calcium signaling during convergent extension in Xenopus. Curr. Biol. 11, 652-661. doi: 10.1016/s0960-9822(01)00201-9

Wallingford, J. B., and Harland, R. M. (2001). Xenopus Dishevelled signaling regulates both neural and mesodermal convergent extension: parallel forces elongating the body axis. Development 128, 2581-2592.

Wallingford, J. B., Niswander, L. A., Shaw, G. M., and Finnell, R. H. (2013). The continuing challenge of understanding, preventing, and treating neural tube defects. Science 339:1222002. doi: 10.1126/science.1222002

Wan, J., and Poo, M. (1999). Activity-induced potentiation of developing neuromuscular synapses. Science 285, 1725-1728. doi: 10.1126/science.285. 5434.1725

Wang, G. X., and Poo, M. M. (2005). Requirement of TRPC channels in netrin1 -induced chemotropic turning of nerve growth cones. Nature 434, 898-904. doi: $10.1038 /$ nature 03478

Xiang, Y., Li, Y., Zhang, Z., Cui, K., Wang, S., Yuan, X. B., et al. (2002). Nerve growth cone guidance mediated by G protein-coupled receptors. Nat. Neurosci. 5, 843-848. doi: 10.1038/nn899

Xu, S., Cheng, F., Liang, J., Wu, W., and Zhang, J. (2012). Maternal xNorrin, a canonical Wnt signaling agonist and TGF- $\beta$ antagonist, controls early neuroectoderm specification in Xenopus. PLoS Biol. 10:e1001286. doi: 10.1371/journal.pbio.1001286

Zhang, H. Y., Issberner, J., and Sillar, K. T. (2011). Development of a spinal locomotor rheostat. Proc. Natl. Acad. Sci. U S A 108, 11674-11679. doi: 10.1073/pnas.1018512108

Zheng, J. Q., Felder, M., Connor, J. A., and Poo, M. M. (1994). Turning of nerve growth cones induced by neurotransmitters. Nature 368, 140-144 doi: $10.1038 / 368140 \mathrm{a} 0$

Conflict of Interest Statement: The author declares that the research was conducted in the absence of any commercial or financial relationships that could be construed as a potential conflict of interest.

Copyright (C) 2017 Borodinsky. This is an open-access article distributed under the terms of the Creative Commons Attribution License (CC BY). The use, distribution or reproduction in other forums is permitted, provided the original author(s) or licensor are credited and that the original publication in this journal is cited, in accordance with accepted academic practice. No use, distribution or reproduction is permitted which does not comply with these terms. 